Cervical and amniotic fluid matrix metalloproteinase-8 and interleukin- 6 concentrations in preterm pregnancies with or without preterm premature rupture of membranes

\author{
Holmström, Emilia
}

2019

Holmström , E , Myntti , T , Sorsa , T , Kruit , H , Juhila , J, Paavonen , J , Rahkonen , L \&

Stefanovic, V 2019 , ' Cervical and amniotic fluid matrix metalloproteinase-8 and interleukin-6 concentrations in preterm pregnancies with or without preterm premature pÿrupture of membranes ' , Fetal Diagnosis and Therapy , vol. 46 , no. 2 , pp. 103110 . https://doi.org/10.1159/0004

http://hdl.handle.net/10138/305206

https://doi.org/10.1159/000493207

publishedVersion

Downloaded from Helda, University of Helsinki institutional repository.

This is an electronic reprint of the original article.

This reprint may differ from the original in pagination and typographic detail.

Please cite the original version. 
Fetal Diagnosis aur Therapy
Fetal Diagn Ther 2019;46:103-110

DOI: $10.1159 / 000493207$
Received: June 4, 2018

Accepted after revision: August 24, 2018

Published online: October 11, 2018

\title{
Cervical and Amniotic Fluid Matrix Metalloproteinase-8 and Interleukin-6 Concentrations in Preterm Pregnancies with or without Preterm Premature Rupture of Membranes
}

\author{
Emilia Holmström ${ }^{a}$ Tarja Myntti ${ }^{a}$ Timo Sorsa $^{\text {b-d }}$ Heidi Kruit $^{a}$ Juuso Juhila ${ }^{e}$ \\ Jorma Paavonen ${ }^{a}$ Leena Rahkonen ${ }^{\text {a }}$ Vedran Stefanovic ${ }^{a}$ \\ ${ }^{a}$ Department of Obstetrics and Gynecology, Helsinki University Hospital and University of Helsinki, Helsinki, \\ Finland; ${ }^{b}$ Department of Oral and Maxillofacial Diseases, Helsinki University Hospital, Helsinki, Finland; ${ }^{\mathrm{C} I n s t i t u t e}$

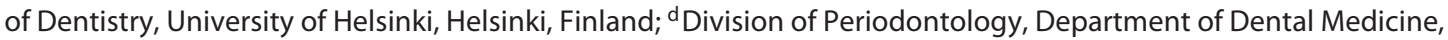 \\ Karolinska Institutet, Huddinge, Sweden; ${ }^{~}$ Medix Biochemica, Espoo, Finland
}

\section{Keywords}

Cervical biomarkers . Preterm premature rupture of membranes - Chorioamnionitis · Biochemical markers . Matrix metalloproteinase-8 $\cdot$ Interleukin-6 $\cdot$ Amniocentesis . Noninvasive sampling · Preterm labor $\cdot$ Intra-amniotic inflammation

\footnotetext{
Abstract

Introduction: Intra-amniotic inflammation is defined by elevated inflammatory biomarkers in the amniotic fluid (AF), either due to microbial invasion of the amniotic cavity (MIAC) or sterile inflammation. Amniocentesis being an invasive procedure, we wanted to investigate whether elevated matrix metalloproteinase-8 (MMP-8) or interleukin-6 (IL-6) concentrations could be detected from cervical fluid samples. Materials and Methods: This prospective study included 67 women with singleton nondiabetic pregnancies with or without preterm premature rupture of membranes (PPROM) between $22^{+0}$ and $37^{+0}$ weeks of gestation. Simultaneous AF and cervical samples were obtained. Results: In women without PPROM, cervical MMP-8 concentrations correlated
}

(c) 2018 S. Karger AG, Basel

E-Mail karger@karger.com www.karger.com/fdt with AF MMP-8 concentrations $\left(r_{\mathrm{S}}=0.466, p=0.002\right)$, but cervical IL-6 did not correlate with AF IL-6 $\left(r_{\mathrm{S}}=0.277, p=\right.$ 0.076). In PPROM cases no correlations were found. Women with MIAC had higher concentrations of AF MMP-8 and AF IL-6 compared to women without MIAC regardless of membrane status. However, only women without PPROM had higher concentrations of cervical MMP-8 in proven MIAC. Conclusion: In women without PPROM, cervical MMP-8 concentration reflects the magnitude of AF MMP-8, thus potentially guiding the selection of patients benefitting from amniocentesis.

(c) 2018 S. Karger AG, Basel

\section{Introduction}

Matrix metalloproteinase-8 (MMP-8), a collagencleaving enzyme released by neutrophils, is a key component in the degradation of extracellular matrix in conditions such as periodontitis, cardiovascular disease, rheumatoid arthritis, and cancer [1-3]. Interleukin-6 (IL-6), a proinflammatory cytokine secreted by macrophages and 
$\mathrm{T}$ cells in tissue damage and inflammation, is an important mediator in host response to infections and various autoimmune diseases [4-6]. During pregnancy, elevated levels of cervical and amniotic fluid (AF) MMP-8 and IL-6 have been linked to the process of cervical ripening and the impending onset of labor [7-12].

Over the last two decades, these biomarkers have been extensively studied as predictors of intra-amniotic inflammation (IAI) [13-20]. IAI is characterized by either sterile inflammation or inflammation due to microbial invasion of the amniotic cavity (MIAC) [21-23]. IAI is a major cause of preterm birth regardless of prelabor membrane status [24-26]. MIAC increases the risk of neonatal morbidity $[27,28]$, but mounting evidence indicates that sterile inflammation without microbial involvement may also lead to poor perinatal outcome $[22,25]$.

Clinical chorioamnionitis constitutes only a small proportion of all IAI cases, most remaining subclinical with minor or unspecific symptoms [29]. In such situations, amniocentesis may provide crucial information for clinical decision-making. The IAI diagnosis is based on the detection of inflammatory biomarkers in AF or, in the case of MIAC, on positive bacterial cultures or molecular microbiology methods. Despite its safety [30], amniocentesis remains an invasive procedure requiring special skills [31,32], and efforts have been made to develop noninvasive biomarker sampling techniques in the diagnosis of IAI [33-37].

The aim of this study was to evaluate the correlations of cervical and AF MMP-8 and IL- 6 concentrations, and to investigate whether the levels of these amniotic inflammatory biomarkers could be assessed with noninvasive cervical swab samples.

\section{Materials and Methods}

This prospective cohort study of 67 women with singleton pregnancies between $22^{+0}$ and $37^{+0}$ weeks of gestation undergoing amniocentesis was performed at the Department of Obstetrics and Gynecology, Helsinki University Hospital, Finland, from June 2013 to July 2017.

Ultrasound-guided transabdominal amniocentesis was performed by an experienced perinatologist in sterile conditions for suspected IAI ( $n=55)$, assessment of fetal lung maturity $(n=8)$, trisomy-PCR or karyotype assessment $(n=3)$, or amnioreduction for polyhydramnios $(n=1)$. A cervical swab sample was obtained simultaneously by inserting a sterile swab into the cervical canal and rotating it for $15 \mathrm{~s}$ during speculum examination. The swabs were then each swirled in their respective extraction solution for $15 \mathrm{~s}$.

Women with insulin-dependent diabetes mellitus, vaginal bleeding, or fetal chromosomal abnormality were excluded from
Table 1. Characteristics of the study population $(n=67)$
Maternal age $\geq 37$ years

Nulliparous

Body mass index $\geq 30$

Smoking

In vitro fertilization

Gestational diabetes

Gestational age at sampling, weeks

Gestational age at delivery, weeks

PPROM prior to sampling

PPROM to sampling interval, weeks

Sampling to birth interval, weeks

Preterm delivery $<37$ gestational weeks

Delivery ( $<32$ gestational weeks)

Suspected IAI

MIAC $^{\mathrm{a}}$

Corticosteroids ${ }^{\mathrm{b}}$

Antibiotics $^{\mathrm{b}}$

Vaginal progesterone ${ }^{\mathrm{b}}$

Nonsteroidal anti-inflammatory drugs ${ }^{\mathrm{b}}$
$6(9.4 \%)$

$27(40.3 \%)$

$15(22.4 \%)$

$11(16.4 \%)$

$3(4.5 \%)$

$15(22.4 \%)$

$28.80 \pm 3.40$

$32.63 \pm 5.07$

$25(37.3 \%)$

$1.61 \pm 2.58$

$3.63 \pm 4.76$

$49(73.1 \%)$

$29(43.3 \%)$

$55(82.1 \%)$

$21(31.3 \%)$

$39(58 \%)$

$31(46 \%)$

$5(7 \%)$

$10(15 \%)$
Values are presented as $n(\%)$ or mean \pm standard deviation. IAI, intra-amniotic inflammation; MIAC, microbial invasion of the amniotic cavity; PPROM, preterm premature rupture of membranes. ${ }^{\mathrm{a}} \mathrm{PCR}$ with or without bacterial culture. ${ }^{\mathrm{b}}$ Use within 1 week prior to sampling.

the study. Women with and without preterm premature rupture of membranes (PPROM) were both included, but the results were assessed in separate subgroups. Gestational age was determined by the crown-rump length at the time of the first-trimester ultrasonography screening.

PPROM was diagnosed with a positive insulin-like growth factor binding protein test (ActimProm; Medix Biochemica, Espoo, Finland). Women with PPROM were managed following the current clinical guidelines, including routine administration of cefuroxime $1.5 \times 3 \mathrm{~g}$ intravenously for 3 consecutive days and a single dose of azithromycin $1 \mathrm{~g}$ orally on admission. Women presenting with imminent labor before the 35th week of gestation received antenatal corticosteroids regardless of membrane status. The use of antenatal steroids, antibiotics, vaginal progesterone, and nonsteroidal anti-inflammatory drugs used by the women within 1 week prior to sampling is given in Table 1 .

IAI was suspected in the presence of contractions with at least one of the following criteria: uterine tenderness, fetal tachycardia, infectious cervical discharge, increased maternal plasma C-reactive protein $>10 \mathrm{mg} / \mathrm{L}$, total blood white cell count $>20 \times 10^{9} / \mathrm{L}$, or visible sludge during transvaginal ultrasound examination. Decisions concerning the management of suspected IAI were left to the attending physician's discretion. The clinicians were blinded to the cervical and AF MMP- 8 and IL- 6 results.

MIAC was defined as a positive AF culture or bacterial $16 \mathrm{~S}$ rDNA gene sequencing (AF-PCR). AF-PCR was performed for each sample, and in 50 (75\%) cases an additional bacterial culture was available. For the bacterial AF-PCR a minimum of $500 \mu \mathrm{L}$ of AF was subjected to ceramic bead-beating cell lysis (Precellys ${ }^{\circledR} 24$ 
Table 2. Concentrations of cervical and AF MMP-8 and IL-6 (ng/mL)

\begin{tabular}{llclrll}
\hline & & $\begin{array}{l}\text { No PPROM } \\
(n=42)\end{array}$ & $\begin{array}{l}\text { PPROM } \\
(n=25)\end{array}$ & $p$ value & $\begin{array}{l}\text { Adjusted } \\
p \text { value }^{\mathrm{a}}\end{array}$ & $\begin{array}{l}\text { Adjusted } \\
p \text { value } 2^{\mathrm{b}}\end{array}$ \\
\hline MMP-8 & AF & $10(2.1-9,753)$ & $396(6.8-16,166)$ & $<0.001$ & 0.133 & 0.143 \\
& cervix & $745(7.8-7,598)$ & $949(0.3-2,719)$ & 0.805 & 0.254 & 0.233 \\
\hline IL-6 & AF & $0.95(0.1-576)$ & $15(0.5-367)$ & 0.007 & 0.371 & 0.371 \\
& cervix & $0.4(0.01-35)$ & $0.7(0.001-21)$ & 0.377 & 0.171 & 0.148 \\
\hline
\end{tabular}

Values are presented as median (range). AF, amniotic fluid; IL-6, interleukin-6; MMP-8, matrix metalloproteinase-8; PPROM, preterm premature rupture of membranes. ${ }^{\text {a }}$ Adjusted for gestational age at sampling. ${ }^{\mathrm{b}}$ Adjusted for gestational age at sampling, corticosteroids, antibiotics, vaginal progesterone, and nonsteroidal anti-inflammatory drug use within 1 week prior to sampling.

tissue homogenizer; Bertin Technologies, France) followed by magnetic-bead-based DNA extraction method (NucliSENS kit with easyMAG automatic nucleic acid purification platform; bioMérieux, Marcy l'Étoile, France) as described by the manufacturer. The extracted DNA was amplified in duplicate by PCR using the following primers: $5^{\prime}$-TTG GAG AGT TTG ATC MTG GCT C-3' (forward) and $5^{\prime}$-GTA TTA CCG CGG CTG CTG-3' (reverse). DNA of lambda phage served as an inhibition control in the PCR reaction. A positive PCR product was verified by gel electrophoresis, $5 \mu \mathrm{L}$ of the PCR product was sequenced in a core facility, and the obtained sequence was compared to the NCBI BLAST sequence database (www.ncbi.nlm.nih.gov/blast). Mixed sequences were analyzed by RipSeq mixed analysis tool (https://www.ripseq. $\mathrm{com} /$ ) when appropriate.

The AF samples of 50 (75\%) women were also cultured in both aerobic and anaerobic conditions, on chocolate blood agar in 5\% $\mathrm{CO}_{2}$ and on fastidious anaerobe agar at $35 \pm 1^{\circ} \mathrm{C}$ with thioglycolate broth enrichment, enabling also the detection of common Candida species and Mycoplasma hominis, but not Ureaplasma species. The samples were cultured for 7 days and the results were inspected after days 1, 2, and 7.

Both AF and cervical sample solutions were frozen and stored at $-20^{\circ} \mathrm{C}$ until analysis of MMP- 8 and IL- 6 concentrations. AF MMP-8 was quantified with a solid-phase immunoenzymometric assay (MMP-8 IEMA; Medix Biochemica, Espoo, Finland) in which microplate wells are coated with a monoclonal antibody against MMP-8 and the secondary antibody is conjugated to horseradish peroxidase, forming the enzyme conjugate used to detect the presence of human MMP-8. The analysis was performed according to the manufacturer's protocol and absorbance was measured at $414 \mathrm{~nm}$ with a microplate reader (Multiskan; Thermo Fisher Scientific, Vantaa, Finland). For IL-6 assessment, a commercial quantitative enzyme immunoassay kit (Quantikine ELISA, human IL-6; R\&D Systems, Minneapolis, MN, USA) was used. Absorbance was measured at $450 \mathrm{~nm}$ with a microplate reader.

Statistical analyses were performed using IBM SPSS Statistics version 24 (Armonk, NY, USA). Categorical variables were compared by the $\chi^{2}$ test or Fisher's exact test. Data with continuous variables not following a normal distribution were compared by the Mann-Whitney U test. Spearman's correlation was used to determine the relationship of two continuous variables. Biomarker concentrations were adjusted for gestational age at sample collection, time interval between PPROM and sampling, antenatal steroids, antibiotics, vaginal progesterone, and nonsteroidal anti-inflammatory drugs used within 1 week prior to sampling. A $p$ value $<0.05$ was considered significant.

\section{Results}

A total of 67 women with a mean gestational age of $28^{+6}$ weeks (range $22^{+1}-36^{+4}$ ) at the time of sampling were enrolled. Of these women, 25 (37\%) had PPROM prior to sampling, the median PPROM to sampling interval being 1.61 weeks (range $0-8.85$ weeks) (Table 1 ). There was no statistically significant difference between the mean gestational age at sampling in women with or without PPROM $\left(28^{+4}\right.$ and $29^{+0}$ weeks, respectively, $\left.p=0.761\right)$. Women with proven MIAC had a significantly lower mean gestational age at sampling than women without MIAC $\left(26^{+6}\right.$ and $29^{+5}$ weeks, respectively, $\left.p=0.008\right)$. Of the women who underwent amniocentesis due to suspected IAI ( $n=55,82 \%), 21$ (31\%) had MIAC. None of the 12 women undergoing amniocentesis for other reasons were diagnosed with MIAC (Table 1).

The median concentrations of AF MMP-8 and AF IL-6 were higher in women with PPROM than in women with intact membranes. However, after adjusting for gestational age at sampling, the differences were not significant. The median cervical MMP- 8 and IL- 6 concentrations did not differ between women with or without PPROM (Table 2).

In the women without PPROM, cervical MMP-8 concentrations correlated with AF MMP-8 concentrations $\left(r_{S}=0.466, p=0.002\right)$, but cervical IL-6 did not correlate with AF IL-6 $\left(r_{\mathrm{S}}=0.277, p=0.076\right)$ (Fig. 1$)$. In women 

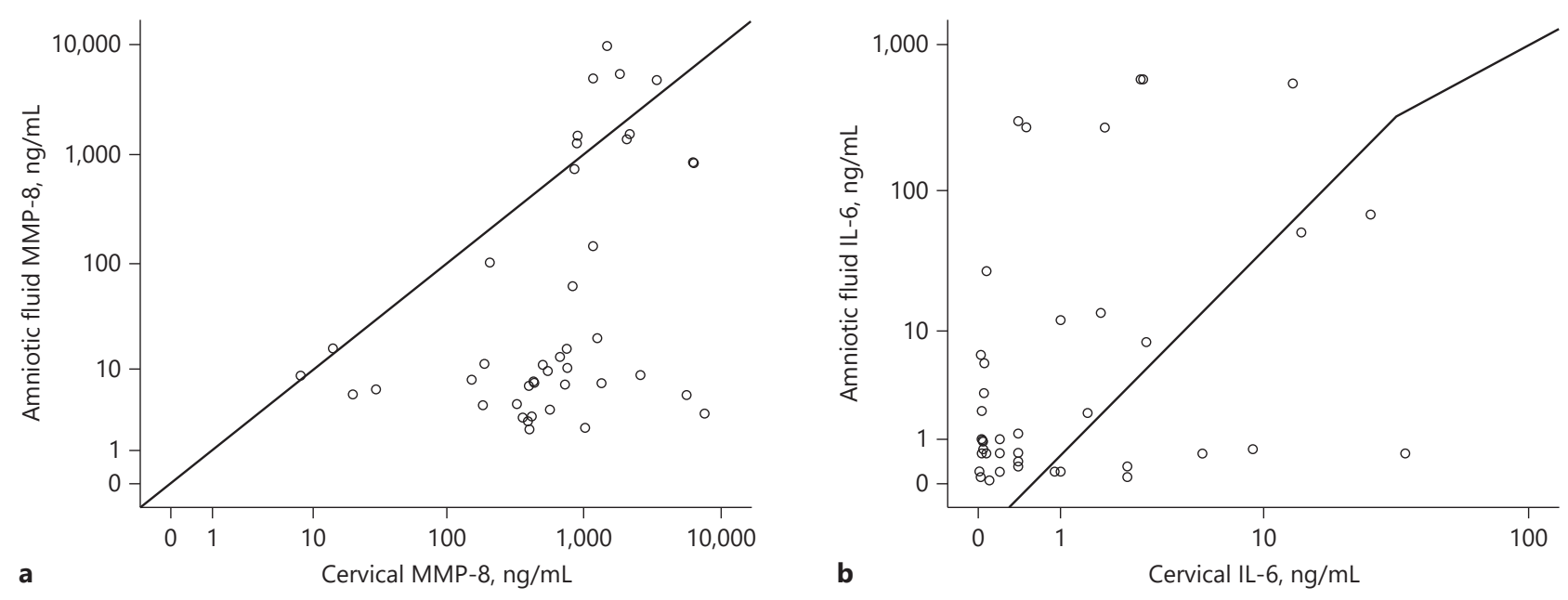

Fig. 1. Correlation of MMP-8 (a) and IL-6 (b) concentrations in amniotic and cervical fluids in women without preterm premature rupture of membranes. Correlation values were $r_{\mathrm{S}}=0.466, p=0.002$ for MMP-8 and $r_{\mathrm{S}}=$ $0.277, p=0.076$ for IL-6. IL-6, interleukin-6; MMP-8, matrix metalloproteinase-8.
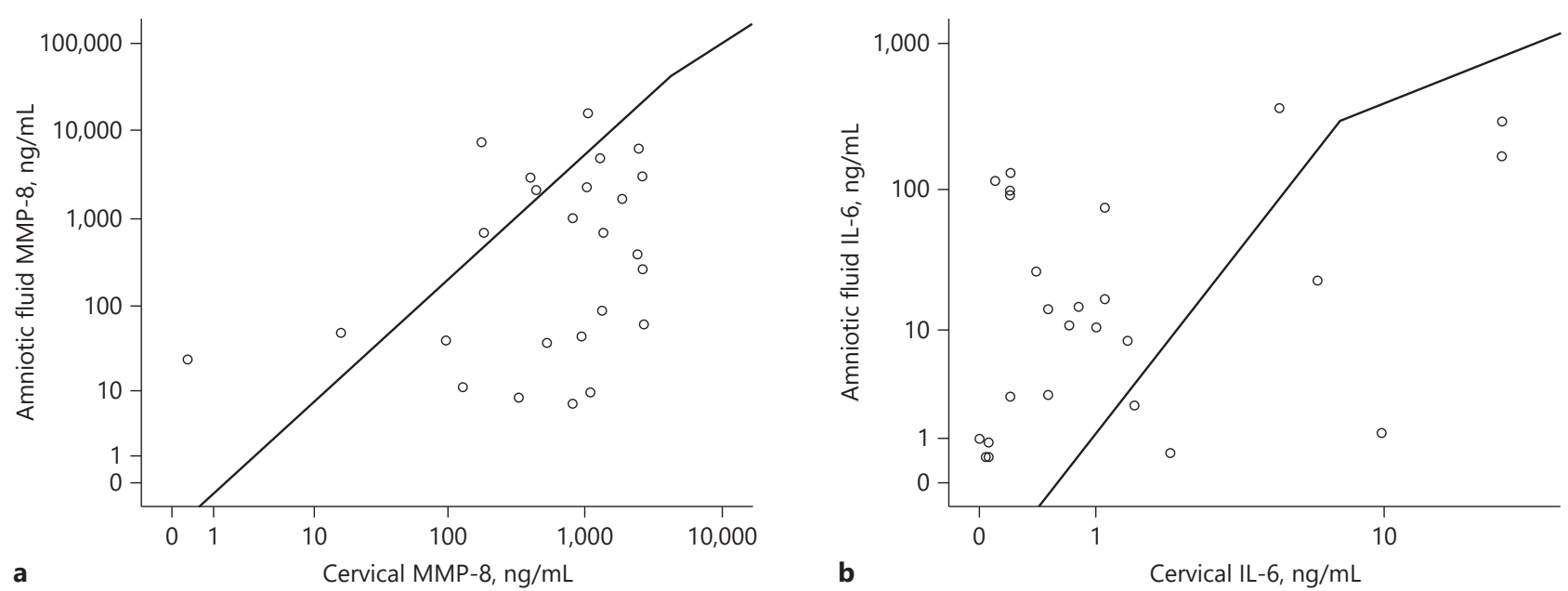

Fig. 2. Correlation of MMP-8 (a) and IL-6 (b) concentrations in amniotic and cervical fluids in women with preterm premature rupture of membranes. Correlation values were $r_{\mathrm{S}}=0.319, p=0.120$ for MMP-8 and $r_{\mathrm{S}}=0.346$, $p=0.090$ for IL-6. IL-6, interleukin-6; MMP-8, matrix metalloproteinase-8.

with PPROM, no correlations between cervical and AF MMP-8 $\left(r_{\mathrm{S}}=0.319, p=0.120\right)$ or cervical and AF IL-6 $\left(r_{\mathrm{S}}=0.346, p=0.090\right)$ occurred (Fig. 2$)$.

In women without PPROM, the median concentrations of AF MMP-8, AF IL-6, and cervical MMP-8 were higher in cases with MIAC $(n=11)$ than in cases without
MIAC $(n=31)$. After adjusting for gestational age at sampling, the differences were not significant. The median concentrations of cervical IL- 6 did not differ between the subgroups with and without MIAC (Table 3 ).

In women with PPROM, the median concentrations of AF MMP-8 and AF IL-6 were higher among women with 
Table 3. Concentrations of cervical and AF MMP-8 and IL-6 (ng/mL) in cases with intact (no PPROM) or ruptured membranes (PPROM) in the presence or absence of MIAC

\begin{tabular}{|c|c|c|c|c|c|c|c|}
\hline & & \multicolumn{2}{|l|}{ No PPROM } & \multirow[t]{2}{*}{$p$ value } & \multirow{2}{*}{$\begin{array}{l}\text { Adjusted } \\
p \text { value }^{\mathrm{a}}\end{array}$} & \multirow{2}{*}{$\begin{array}{l}\text { Adjusted } \\
p \text { value } 2^{\mathrm{b}}\end{array}$} & \\
\hline & & MIAC $(n=11)$ & no MIAC $(n=31)$ & & & & \\
\hline \multirow[t]{2}{*}{ MMP-8 } & \multirow{2}{*}{$\begin{array}{l}\text { AF } \\
\text { cervix }\end{array}$} & $1,483(144-9,754)$ & $7.2(2.1-1,260)$ & $<0.001$ & 0.396 & \multirow{2}{*}{\multicolumn{2}{|c|}{$\begin{array}{l}0.498 \\
0.201\end{array}$}} \\
\hline & & $1,845(860-6,344)$ & $440(7.8-7,598)$ & $<0.001$ & 0.110 & & \\
\hline \multirow[t]{4}{*}{ IL-6 } & \multirow{4}{*}{$\begin{array}{l}\text { AF } \\
\text { cervix }\end{array}$} & $269(5.6-576)$ & $0.6(0.1-13.7)$ & $<0.001$ & 0.062 & 0.081 & \\
\hline & & $1.9(0.2-26)$ & $0.4(0.01-35)$ & 0.110 & 0.612 & 0.822 & \\
\hline & & \multicolumn{2}{|l|}{ PPROM } & \multirow[t]{2}{*}{$p$ value } & \multirow{2}{*}{$\begin{array}{l}\text { Adjusted } \\
p \text { value }^{\mathrm{a}}\end{array}$} & \multirow{2}{*}{$\begin{array}{l}\text { Adjusted } \\
p \text { value } 2^{\mathrm{b}}\end{array}$} & \multirow{2}{*}{$\begin{array}{l}\text { Adjusted } \\
p \text { value } 3^{c}\end{array}$} \\
\hline & & MIAC $(n=10)$ & no MIAC $(n=15)$ & & & & \\
\hline \multirow[t]{2}{*}{ MMP-8 } & \multirow{2}{*}{$\begin{array}{l}\text { AF } \\
\text { cervix }\end{array}$} & $1,911(45-6,290)$ & $49.0(6.8-16,166)$ & 0.041 & 0.055 & 0.080 & 0.048 \\
\hline & & $1,177(186-2,665)$ & $818.9(0.3-2,719)$ & 0.196 & 0.567 & 0.605 & 0.261 \\
\hline \multirow[t]{2}{*}{ IL-6 } & \multirow{2}{*}{$\begin{array}{l}\mathrm{AF} \\
\text { cervix }\end{array}$} & $83.5(1.2-367)$ & $3.0(0.5-170)$ & 0.010 & 0.019 & 0.062 & 0.016 \\
\hline & & $0.95(0.2-21)$ & $0.50(0.001-21)$ & 0.144 & 0.311 & 0.397 & 0.285 \\
\hline
\end{tabular}

Values are presented as median (range). AF, amniotic fluid; IL-6, interleukin-6; MIAC, microbial invasion of the amniotic cavity; MMP-8, matrix metalloproteinase-8; PPROM, preterm premature rupture of membranes. a Adjusted for gestational age at sampling. ${ }^{b}$ Adjusted for gestational age, corticosteroid, antibiotics, vaginal progesterone, and nonsteroidal anti-inflammatory drug use within 1 week prior to sampling. ${ }^{c}$ Adjusted for time interval between PPROM and sampling.

MIAC $(n=10)$ than in women without MIAC $(n=15)$. These differences were similarly not significant after adjusting for gestational age at sampling. Cervical MMP-8 and IL- 6 concentrations did not differ between those with and without MIAC (Table 3).

The microbial findings in AF samples are given in Table 4 .

\section{Discussion}

Our results demonstrated a correlation between the cervical and AF MMP-8 concentrations in women with intact membranes, but not in women with PPROM. No correlation between the concentrations of cervical and AF IL- 6 was seen. Regardless of membrane status, women with MIAC had higher concentrations of AF MMP-8 and IL-6 compared to women without MIAC. In addition, the women without PPROM also had higher cervical concentrations of MMP-8 if they had MIAC compared to those not having MIAC, suggesting that cervical MMP-8 may have potential as a noninvasively obtainable biomarker for IAI, at least for women with intact membranes. There were no statistical differences between MIAC and nonMIAC women after adjusting for gestational age at sam- pling. However, this observation was expected, since the women with MIAC had significantly lower gestational age at sampling.

We acknowledge the major weakness of our study having a relatively small sample size. However, the clinical setting combined to the study's prospective nature and the simultaneous cervical and AF sampling offset this lack of power. To our best knowledge, this is the only study investigating the correlation between cervical and $\mathrm{AF}$ MMP-8, comparing the biomarker levels with and without PPROM and investigating cervical MMP-8 in MIAC patients. We are also aware of the possible confounding factors, such as administration of antenatal steroids and antibiotics during the study. Therefore, we adjusted the results for antenatal steroids, antibiotics, vaginal progesterone, and nonsteroidal anti-inflammatory drugs used within 1 week prior to sampling, but this did not change the results. Unfortunately, although AF-PCR was performed in all AF samples, bacterial cultures of 17 (25\%) samples were lacking, which may have affected the detection of some microbial flora. However, it has been previously demonstrated that the number of bacterial species revealed by PCR is greater than that by cultures and includes as yet uncultivated taxa, and that the detection of MIAC by molecular methods has clinical significance 
Table 4. Microbiologic findings in amniocentesis samples

\begin{tabular}{rlll}
\hline Case & PPROM & PCR & Culture \\
No. & positive/negative & & \\
\hline 1 & positive & Peptostreptococcus anaerobius + & Peptostreptococcus anaerobius + \\
& & Streptococcus anginosus & Streptococcus anginosus \\
2 & negative & Streptococcus pneumoniae & Streptococcus pneumoniae \\
3 & negative & Eschericia coli + & Eschericia coli \\
& & Fusobacterium nucleatum & \\
4 & negative & Mycoplasma hominis & Mycoplasma hominis \\
5 & negative & Lactobacillus jensenii & Lactobacillus jensenii \\
6 & positive & Ureaplasma urealyticum & Streptococcus anginosus \\
7 & negative & Ureaplasma urealyticum & negative \\
8 & negative & Bacteroides ureolyticus & negative \\
9 & positive & Ureaplasma urealyticum & negative \\
10 & negative & Ureaplasma urealyticum & negative \\
11 & negative & Ureaplasma urealyticum & negative \\
12 & positive & Ureaplasma urealyticum & negative \\
13 & negative & Ureaplasma urealyticum & negative \\
14 & positive & Ureaplasma urealyticum & negative \\
15 & positive & Ureaplasma urealyticum & negative \\
16 & positive & Ureaplasma urealyticum & negative \\
17 & negative & Fusobacterium nucleatum & negative \\
18 & positive & Streptococcus viridans & negative \\
19 & positive & Lactobacillus crispatus & NA \\
20 & positive & negative & Candida albicans \\
21 & negative & negative & Candida albicans \\
\hline & nation &
\end{tabular}

NA, not available; PCR, polymerase chain reaction implemented for $16 \mathrm{~S}$ rDNA detection; PPROM, preterm premature rupture of membranes.

[38]. We analyzed women with intact membranes and PPROM separately, since the clinical treatment and the origin of inflammation may differ between these groups [39]. We also studied both nulliparous and multiparous women, as parity-related variation in MMP- 8 concentrations has previously been reported $[11,40]$.

To the best of our knowledge, our current study is the first to address the correlation of cervical and AF MMP-8. We detected this correlation only in women without PPROM. Prior PPROM may have interfered with the detection of cervical MMP-8, or the negative result may be due to type II error caused by the small sample size. In addition, the mean PPROM to sampling interval was as long as 1.6 weeks, and the routine administration of antibiotics in PPROM might also have modified the intensity of the inflammatory response [41]. In order to consider the significance of the relatively long PPROM to sampling interval, we adjusted the results in women with PPROM for this potential confounder. However, the results did not change.
Holst et al. [42] found a weak correlation between cervical and AF IL-6 in women without PPROM, but this was not seen in our study. Musilova et al. [36] observed a strong correlation between vaginal and AF IL- 6 concentrations in women with PPROM. However, their approach to sampling differed from ours (collection of AF from the vagina with a special syringe versus swab), which may explain some of the differences in the results.

Higher concentrations of AF MMP-8 were detected in women with PPROM than in women with intact membranes, as also reported by previous studies [7, 17]. However, this difference disappeared when we adjusted for gestational age at sampling, suggesting that gestational age and MIAC status are more important than membrane status. We found no difference in the cervical MMP-8 and IL- 6 concentrations of women with or without PPROM.

We detected elevated concentrations of AF IL- 6 in women with PPROM compared to women with intact membranes when MIAC status was not taken into consideration. This difference also disappeared when we ad- 
justed for gestational age. Lee et al. [43] separately assessed IAI and non-IAI cases, detecting no significant difference in the AF IL- 6 concentrations between PPROM and non-PPROM in non-IAI cases. However, in women with IAI, the levels of AF IL-6 were decreased in PPROM cases. A similar trend was seen in our study, in which the women with MIAC and intact membranes also showed higher median concentrations of AF IL- 6 than the women with MIAC and PPROM, although statistical difference was not reached ( $p=0.387$ ), perhaps due to the small sample size. Nevertheless, this may reflect a possible progression in the IAI sequence: the initial AF IL-6 peak followed by PPROM.

We observed that, regardless of membrane status, patients with MIAC had significantly higher concentrations of AF MMP-8 and IL- 6 than those without MIAC, which is in line with previous IAI studies [19, 20,22]. Moreover, cervical MMP-8 concentrations were higher in the subgroup of women without PPROM and with MIAC compared to women without PPROM and MIAC. Interestingly, this was not the case with cervical IL-6. On the contrary, a correlation of high cervical IL- 6 and MIAC was previously observed both in women with and without PPROM [44, 45]. Holst et al. [42] investigated an array of different possible cervical biomarkers for MIAC in women without PPROM and found that cervical IL-6 was a good biomarker candidate. The difference in our results may be explained by the different detection methods, i.e., multiplex technology versus conventional ELISA.

\section{Conclusion}

Cervical MMP-8 and IL-6 concentrations do not reflect the exact intra-amniotic concentrations of these markers. Nevertheless, in women without PPROM, cervical MMP-8 concentration reflects the magnitude of AF MMP-8, thus potentially guiding the selection of patients benefitting from amniocentesis. Future studies with larger sample sizes are needed to define a clinically useful cutoff value for cervical MMP-8.

\section{Acknowledgments}

We thank the staff of Helsinki University Hospital for help in collecting the samples and the staff of Medix Biochemica for analyses of the samples. This study was supported by the SalWe Research Program "Get it done" (Tekes - The Finnish Funding Agency for Technology and Innovation) and by a Helsinki University Hospital research grant.

\section{Statement of Ethics}

Subjects gave their written informed consent. The study protocol was approved by the ethics committee of Helsinki University Hospital (75/13/03/03/2013) and the Hospital District of Helsinki and Uusimaa.

\section{Disclosure Statement}

The authors have no conflicts of interest to declare.

\section{References}

1 Rathnayake N, Gieselmann DR, Heikkinen AM, Tervahartiala T, Sorsa T. Salivary Diagnostics-Point-of-Care diagnostics of MMP-8 in dentistry and medicine. Diagnostics (Basel). 2017 Jan;7(1):E7.

2 Tokito A, Jougasaki M. Matrix Metalloproteinases in Non-Neoplastic Disorders. Int J Mol Sci. 2016 Jul;17(7):E1178.

3 Dejonckheere E, Vandenbroucke RE, Libert C. Matrix metalloproteinase8 has a central role in inflammatory disorders and cancer progression. Cytokine Growth Factor Rev. 2011 Apr;22(2):73-81.

4 Shapouri-Moghaddam A, Mohammadian S, Vazini H, Taghadosi M, Esmaeili SA, Mardani F, et al. Macrophage plasticity, polarization, and function in health and disease. J Cell Physiol. 2018 Sep;233(9):6425-40.

5 Grevich S, Shenoi S. Update on the management of systemic juvenile idiopathic arthritis and role of IL-1 and IL- 6 inhibition. Adolesc Health Med Ther. 2017 Nov;8:125-35.

6 Chen YL, Qiao YC, Pan YH, Xu Y, Huang YC, Wang YH, et al. Correlation between serum interleukin-6 level and type 1 diabetes mellitus: A systematic review and meta-analysis. Cytokine. 2017 Jun;94:14-20.

7 Maymon E, Romero R, Pacora P, Gomez R, Athayde N, Edwin S, et al. Human neutrophil collagenase (matrix metalloproteinase 8) in parturition, premature rupture of the membranes, and intrauterine infection. Am J Obstet Gynecol. 2000 Jul;183(1):94-9.

8 Sennström MB, Brauner A, Byström B, Malmström A, Ekman G. Matrix metalloproteinase- 8 correlates with the cervical ripening process in humans. Acta Obstet Gynecol Scand. 2003 Oct;82(10):904-11.

9 Nien JK, Yoon BH, Espinoza J, Kusanovic JP, Erez O, Soto E, et al. A rapid MMP-8 bedside test for the detection of intra-amniotic inflammation identifies patients at risk for imminent preterm delivery. Am J Obstet Gynecol. 2006 Oct;195(4):1025-30.

10 Holst RM, Hagberg H, Wennerholm UB, Skogstrand K, Thorsen P, Jacobsson B. Prediction of spontaneous preterm delivery in women with preterm labor: analysis of mul- tiple proteins in amniotic and cervical fluids. Obstet Gynecol. 2009 Aug;114(2 Pt 1):26877.

11 Rahkonen L, Rutanen EM, Nuutila M, Sainio S, Sorsa T, Paavonen J. Matrix metalloproteinase- 8 in cervical fluid in early and mid pregnancy: relation to spontaneous preterm delivery. Prenat Diagn. 2010 Nov;30(11): 1079-85.

12 Kim SM, Romero R, Lee J, Chaemsaithong P, Lee MW, Chaiyasit N, et al. About one-half of early spontaneous preterm deliveries can be identified by a rapid matrix metalloproteinase- 8 (MMP-8) bedside test at the time of mid-trimester genetic amniocentesis. J Matern Fetal Neonatal Med. 2016;29(15):241422.

13 Kim KW, Romero R, Park HS, Park CW, Shim SS, Jun JK, et al. A rapid matrix metalloproteinase- 8 bedside test for the detection of intraamniotic inflammation in women with preterm premature rupture of membranes. Am J Obstet Gynecol. 2007 Sep; 197(3):292.e1-5. 
14 Chaemsaithong P, Romero R, Korzeniewski SJ, Martinez-Varea A, Dong Z, Yoon BH, et al. A point of care test for interleukin- 6 in amniotic fluid in preterm prelabor rupture of membranes: a step toward the early treatment of acute intra-amniotic inflammation/infection. J Matern Fetal Neonatal Med. 2016; 29(3):360-7.

15 Chaemsaithong P, Romero R, Korzeniewski SJ, Martinez-Varea A, Dong Z, Yoon BH, et al. A rapid interleukin- 6 bedside test for the identification of intra-amniotic inflammation in preterm labor with intact membranes. J Matern Fetal Neonatal Med. 2016;29(3):34959.

16 Myntti T, Rahkonen L, Tikkanen M, PätäriSampo A, Paavonen J, Stefanovic V. Amniotic fluid rapid biomarkers are associated with intra-amniotic infection in preterm pregnancies regardless of the membrane status. J Perinatol. 2016 Aug;36(8):606-11.

17 Myntti T, Rahkonen L, Pätäri-Sampo A, Tikkanen M, Sorsa T, Juhila J, et al. Comparison of amniotic fluid matrix metalloproteinase- 8 and cathelicidin in the diagnosis of intra-amniotic infection. J Perinatol. 2016 Dec;36(12) 1049-54.

18 Myntti T, Rahkonen L, Nupponen I, PätäriSampo A, Tikkanen M, Sorsa T, et al. Amniotic Fluid Infection in Preterm Pregnancies with Intact Membranes. Dis Markers. 2017; 2017:8167276.

19 Chaiyasit N, Romero R, Chaemsaithong P, Docheva N, Bhatti G, Kusanovic JP, et al. Clinical chorioamnionitis at term VIII: a rapid MMP-8 test for the identification of intraamniotic inflammation. J Perinat Med. 2017 Jul;45(5):539-50.

20 Chaemsaithong P, Romero R, Docheva N, Chaiyasit N, Bhatti G, Pacora P, et al. Comparison of rapid MMP-8 and interleukin- 6 point-of-care tests to identify intra-amniotic inflammation/infection and impending preterm delivery in patients with preterm labor and intact membranes. J Matern Fetal Neonatal Med. 2018 Jan;31(2):228-44.

21 Romero R, Miranda J, Chaemsaithong P, Chaiworapongsa T, Kusanovic JP, Dong Z, et al. Sterile and microbial-associated intra-amniotic inflammation in preterm prelabor rupture of membranes. J Matern Fetal Neonatal Med. 2015 Aug;28(12):1394-409.

22 Combs CA, Gravett M, Garite TJ, Hickok DE Lapidus J, Porreco R, et al.; ProteoGenix/Obstetrix Collaborative Research Network. Amniotic fluid infection, inflammation, and colonization in preterm labor with intact membranes. Am J Obstet Gynecol. 2014 Feb; 210(2):125.e1-15.

23 Oh KJ, Kim SM, Hong JS, Maymon E, Erez O, Panaitescu B, et al. Twenty-four percent of patients with clinical chorioamnionitis in preterm gestations have no evidence of either culture-proven intraamniotic infection or intraamniotic inflammation. Am J Obstet Gynecol. 2017 Jun;216(6):604.e1-11.
24 Romero R, Espinoza J, Gonçalves LF, Kusanovic JP, Friel L, Hassan S. The role of inflammation and infection in preterm birth. Semin Reprod Med. 2007 Jan;25(1):21-39.

25 Romero R, Miranda J, Chaiworapongsa T, Korzeniewski SJ, Chaemsaithong P, Gotsch $\mathrm{F}$, et al. Prevalence and clinical significance of sterile intra-amniotic inflammation in patients with preterm labor and intact membranes. Am J Reprod Immunol. 2014 Nov; 72(5):458-74.

26 Romero R, Dey SK, Fisher SJ. Preterm labor: one syndrome, many causes. Science. 2014 Aug;345(6198):760-5.

27 Romero R, Gotsch F, Pineles B, Kusanovic JP Inflammation in pregnancy: its roles in reproductive physiology, obstetrical complications, and fetal injury. Nutr Rev. 2007 Dec;65(12 Pt 2):S194-202.

28 Archabald KL, Buhimschi IA, Bahtiyar MO, Dulay AT, Abdel-Razeq SS, Pettker CM, et al. Limiting the Exposure of Select Fetuses to Intrauterine Infection/Inflammation Improves Short-Term Neonatal Outcomes in Preterm Premature Rupture of Membranes. Fetal Diagn Ther. 2017;42(2):99-110.

29 Menon R, Taylor RN, Fortunato SJ. Chorioamnionitis - a complex pathophysiologic syndrome. Placenta. 2010 Feb;31(2):113-20.

30 Musilova I, Bestvina T, Stranik J, Stepan M, Jacobsson B, Kacerovsky M. Transabdominal Amniocentesis Is a Feasible and Safe Procedure in Preterm Prelabor Rupture of Membranes. Fetal Diagn Ther. 2017;42(4):257-61.

31 Beta J, Lesmes-Heredia C, Bedetti C, Akolekar R. Risk of miscarriage following amniocentesis and chorionic villus sampling: a systematic review of the literature. Minerva Ginecol. 2018 Apr;70(2):215-219.

32 Niederstrasser SL, Hammer K, Möllers M, Falkenberg MK, Schmidt R, Steinhard J, et al. Fetal loss following invasive prenatal testing: a comparison of transabdominal chorionic villus sampling, transcervical chorionic villus sampling and amniocentesis. J Perinat Med. 2017 Feb;45(2):193-8.

33 Holst RM, Mattsby-Baltzer I, Wennerholm UB, Hagberg H, Jacobsson B. Interleukin-6 and interleukin- 8 in cervical fluid in a population of Swedish women in preterm labor: relationship to microbial invasion of the amniotic fluid, intra-amniotic inflammation, and preterm delivery. Acta Obstet Gynecol Scand. 2005 Jun;84(6):551-7.

34 Holst RM, Jacobsson B, Hagberg H, Wennerholm UB. Cervical length in women in preterm labor with intact membranes: relationship to intra-amniotic inflammation/microbial invasion, cervical inflammation and preterm delivery. Ultrasound Obstet Gynecol. 2006 Nov;28(6):768-74.

35 Combs CA, Garite TJ, Lapidus JA, Lapointe JP, Gravett M, Rael J, et al.; Obstetrix Collaborative Research Network. Detection of microbial invasion of the amniotic cavity by analysis of cervicovaginal proteins in women with preterm labor and intact membranes. Am J Obstet Gynecol. 2015 Apr;212(4):482. e1-12.

36 Musilova I, Bestvina T, Hudeckova M, Michalec I, Cobo T, Jacobsson B, et al. Vaginal fluid interleukin- 6 concentrations as a pointof-care test is of value in women with preterm prelabor rupture of membranes. Am J Obstet Gynecol. 2016 Nov;215(5):619.e1-12.

37 Cobo T, Kacerovsky M, Jacobsson B. Noninvasive Sampling of the Intrauterine Environment in Women with Preterm Labor and Intact Membranes. Fetal Diagn Ther. 2018; 43(4):241-249.

38 DiGiulio DB, Romero R, Kusanovic JP, Gómez R, Kim CJ, Seok KS, et al. Prevalence and diversity of microbes in the amniotic fluid, the fetal inflammatory response, and pregnancy outcome in women with preterm pre-labor rupture of membranes. Am J Reprod Immunol. 2010 Jul;64(1):38-57.

39 Park CW, Park JS, Moon KC, Jun JK, Yoon $\mathrm{BH}$. Preterm labor and preterm premature rupture of membranes have a different pattern in the involved compartments of acute histologic chorioamnionitis and/or funisitis: patho-physiologic implication related to different clinical manifestations. Pathol Int. 2016 Jun;66(6):325-32.

40 Rahkonen L, Rutanen EM, Unkila-Kallio L, Nuutila M, Nieminen P, Sorsa T, et al. Factors affecting matrix metalloproteinase-8 levels in the vaginal and cervical fluids in the first and second trimester of pregnancy. Hum Reprod. 2009 Nov;24(11):2693-702.

41 Gomez R, Romero R, Nien JK, Medina L, Carstens M, Kim YM, et al. Antibiotic administration to patients with preterm premature rupture of membranes does not eradicate intra-amniotic infection. J Matern Fetal Neonatal Med. 2007 Feb;20(2):167-73.

42 Holst RM, Hagberg H, Wennerholm UB, Skogstrand K, Thorsen P, Jacobsson B. Prediction of microbial invasion of the amniotic cavity in women with preterm labour: analysis of multiple proteins in amniotic and cervical fluids. BJOG. 2011 Jan;118(2):240-9.

43 Lee SY, Buhimschi IA, Dulay AT, Ali UA, Zhao G, Abdel-Razeq SS, et al. IL-6 trans-signaling system in intra-amniotic inflammation, preterm birth, and preterm premature rupture of the membranes. J Immunol. 2011 Mar;186(5):3226-36.

44 Rizzo G, Capponi A, Rinaldo D, Tedeschi D, Arduini D, Romanini C. Interleukin-6 concentrations in cervical secretions identify microbial invasion of the amniotic cavity in patients with preterm labor and intact membranes. Am J Obstet Gynecol. 1996 Oct;175 (4 Pt 1):812-7.

45 Kacerovsky M, Musilova I, Jacobsson B, Drahosova $\mathrm{M}$, Hornychova $\mathrm{H}$, Janku $\mathrm{P}$, et al. Cervical fluid IL-6 and IL-8 levels in pregnancies complicated by preterm prelabor rupture of membranes. J Matern Fetal Neonatal Med. 2015 Jan;28(2):134-40. 